\title{
Articles
}

\section{Causes of weight gain during insulin therapy with and without metformin in patients with Type II diabetes mellitus}

\author{
S. Mäkimattila ${ }^{1}$, K. Nikkilä², H. Yki-Järvinen ${ }^{1}$ \\ ${ }^{1}$ Department of Medicine, Division of Endocrinology and Diabetology, Helsinki University Central Hospital, Helsinki, Finland \\ ${ }^{2}$ Jorvi Central Hospital, Espoo, Finland
}

\begin{abstract}
Aims/hypothesis. To determine causes of weight gain during insulin therapy with and without metformin in Type II (non-insulin-dependent) diabetes mellitus. Methods. Twenty-six patients with Type II diabetes (body mass index $28 \pm 1 \mathrm{~kg} / \mathrm{m}^{2}$ ) were treated with insulin alone $(n=13)$ or insulin and with metformin $(n=13)$. Components of energy balance (basal metabolic rate, energy intake, glucosuria) were measured at 0 and 12 months.

Results. Glycaemic control improved similarly in patients using $\left(\mathrm{HbA}_{1 \mathrm{c}} 10.5 \pm 0.3\right.$ vs $7.6 \pm 0.2 \%$, $p<0.001)$ and not using $(10.2 \pm 0.3$ vs $7.8 \pm 0.3 \%$, $p<0.001$ ) metformin. The metformin group required $47 \%$ less insulin than the group not using metformin $(p<0.001)$. Body weight increased by $3.8 \pm 0.8$ and $7.5 \pm 1.6 \mathrm{~kg}(p<0.05)$, respectively. Basal metabolic
\end{abstract}

rate and glucosuria were similar at 0 and 12 months in both groups but the metformin group decreased energy intake by $1.12 \pm 0.46 \mathrm{MJ} / \mathrm{day}$, whereas it remained unchanged in the other group $(0.15 \pm 0.42$ $\mathrm{MJ} /$ day). Changes in body weight and glycaemia were statistically significant independent determinants of basal metabolic rate. Their change in opposite directions explained why basal metabolic rate remained unchanged.

Conclusion/interpretation. Improved glycaemia promotes weight gain by decreasing both basal metabolic rate and glucosuria. Use of metformin decreases weight gain by reducing energy intake and is therefore a useful adjunct to insulin therapy in patients with Type II diabetes. [Diabetologia (1999) 42: 406-412]

Keywords Leptin, glucosuria, energy balance, glucose.
Despite a good initial response to insulin therapy in patients with Type II (non-insulin-dependent) diabetes mellitus, long-term treatment results are often less satisfactory [1]. The poor treatment results have been attributed to the progressive nature of Type II diabetes and to failure to increase the insulin dose

Received: 3 September 1998 and in final revised form: 4 December 1998

Corresponding author: H. Yki-Järvinen, M.D., University of Helsinki, Department of Medicine, Division of Endocrinology and Diabetology, Haartmaninkatu 4, FIN-00290 Helsinki, Finland

Abbreviations: BMR, Basal metabolic rate; UKPDS, United Kingdom prospective diabetes study; $\mathrm{E}_{\mathrm{IN}}$, energy intake; $\mathrm{E}_{\mathrm{OUT}}$, energy expenditure, MET $+/-$, patients treated with insulin regimens either including $(+)$ or not including $(-)$ metformin. sufficiently to overcome insulin resistance induced by weight gain $[2,3]$. Previous data on the causes of weight gain during insulin therapy in patients with Type II diabetes are sparse. In one study the basal metabolic rate (BMR) was measured before and after 1 year of insulin therapy in eight patients with Type II diabetes, whose weight increased by $3.9 \mathrm{~kg}$, $\mathrm{HbA}_{1 \mathrm{c}}$ decreased by $1.7 \%$ and absolute BMR $(\mathrm{kJ} /$ min) remained unchanged [4]. BMR also remained unchanged in a study of six patients treated for 2 weeks with glyburide and insulin [5]. Glucosuria or dietary intake were not determined in these studies. Another previous study found body weight to increase by $2.1 \mathrm{~kg}$ during combination therapy with sulfonylurea and bedtime insulin and attributed this increase to a reduction in glucosuria but data on BMR or dietary intake were not reported [6]. 
Studies comparing effects of oral agents have suggested that metformin might favourably influence weight gain in patients with Type II diabetes. In the UK prospective diabetes study (UKPDS), obese patients allocated to metformin treatment gained $1 \mathrm{~kg}$ of weight during 6 years but those treated with insulin and sulphonylureas gained 4 and $6 \mathrm{~kg}$, respectively [2]. In the US metformin trial, patients who were switched from glyburide to metformin lost $4.1 \mathrm{~kg}$ of weight compared with those who continued to use glyburide [7]. Glycaemic control improved similarly both in the UKPDS and the US metformin trial in all treatment groups $[2,7]$. The mechanism underlying the beneficial effect of metformin is uncertain but could be due to a decrease in energy intake, since a recent report found hunger ratings and the snacks eaten to be decreased after 3 days of metformin monotherapy [8]. It has previously been suggested that metformin does not change BMR but decreases mildly appetite in patients with Type II diabetes [9]. There are, however, no studies systematically analysing causes of weight gain during insulin therapy or its attenuation during combination therapy with insulin and metformin in patients with Type II diabetes. This study aimed to determine causes of weight gain during 1 year of insulin therapy using regimens either containing or not containing metformin in patients with Type II diabetes.

\section{Subjects and methods}

Study design. The study protocol consisted of a 6-week run-in period and 12 months of insulin therapy. Twenty-six patients with Type II diabetes, 20 men and 6 women, were recruited to the study from diabetes outpatient clinics in the Espoo area based on the following criteria. Inclusion criteria were: 1) age 40 to 70 years, 2) BMI less than $35 \mathrm{~kg} / \mathrm{m}^{2}, 3$ ) fasting blood glucose above $8 \mathrm{mmol} / \mathrm{l}$, 4) duration of diabetes more than 3 years, 5) previous oral therapy with a maximum dose of either glipizide ( $\geq 15 \mathrm{mg} /$ day) or glyburide ( $\geq 10 \mathrm{mg} /$ day), 6 ) fasting serum $C$-peptide above $0.33 \mathrm{nmol} / \mathrm{l}$ (reference range 0.33 to $0.69 \mathrm{nmol} / \mathrm{l})$. Exclusion criteria were: 1) New York Heart Association Functional Class III or IV, heart failure, myocardial infarction, or stroke during the past 6 months, 2) epilepsy or other severe disease, 3 ) liver disease unrelated to diabetes, 4) nephropathy (serum creatinine above $120 \mu \mathrm{mol} / \mathrm{litre}$, or macroalbuminuria), 5) proliferative retinopathy or severe maculopathy, 6) previous insulin therapy for more than 2 weeks, 7) excessive alcohol consumption, 8) night shift.

Visits 6 and 3 weeks before therapy. If accepted for the study based on the inclusion and exclusion criteria, the patients visited the treatment centre 6 weeks prior to the start of insulin therapy. At this visit, the patients were given instruction on home-glucose monitoring. The patients were asked to measure their fasting blood glucose concentration daily, and the diurnal blood glucose profile weekly during the run-in period and the first 3 months of insulin therapy and every other week thereafter. The diurnal home-glucose profile included measurements before and $1 \mathrm{~h} 30 \mathrm{~min}$ after breakfast, lunch and dinner, and at 2200 and at 0400 hours. The patients were also asked to re- cord daily the occurrence of hypoglycaemic symptoms. A fasting blood sample was obtained for measurement of fasting plasma glucose and C-peptide concentrations, $\mathrm{HbA}_{1 \mathrm{c}}$, serum creatinine and liver enzymes. To exclude patients with macroalbuminuria, the urinary albumin excretion rate was determined from an overnight urine collection using an immunoturbidimetric (Hitachi Ltd., Tokyo, Japan) method with an antiserum against human albumin (Orion Diagnostica, Espoo, Finland). Three weeks before initiation of insulin therapy $(-3$ week visit), fasting plasma glucose was measured in the laboratory and by the patient and further education regarding homeglucose monitoring was given if necessary.

Initiation of insulin therapy, self-adjustment of the insulin dose, 0 month visit. At 0 weeks, insulin therapy was started. The initial dosage (IU/day) of bedtime NPH (Insulin Pitkä, 100 IU/ $\mathrm{ml}$, Orion, Espoo, Finland) was equal to the fasting plasma glucose concentration $(\mathrm{mmol} / \mathrm{l})$, e.g. $10 \mathrm{IU}$ for a fasting glucose concentration of $10 \mathrm{mmol} / \mathrm{l}$. The patients were then given written instructions on how to adjust the insulin dosage based on results of home glucose monitoring of the fasting plasma glucose concentration. The patients were instructed to increase the insulin dosage every 3 days by 4 IU/day, if the fasting plasma glucose concentration exceeded $8 \mathrm{mmol} / \mathrm{l}$ and by $2 \mathrm{IU} /$ day, if fasting glucose exceeded $6 \mathrm{mmol} / \mathrm{l}$. The glycaemic target was to decrease the fasting plasma glucose concentration below $6 \mathrm{mmol} / \mathrm{l}$. This was predicted to decrease $\mathrm{HbA}_{1 \mathrm{c}}$ to less than $7.5 \%$ [10]. In addition to bedtime NPH insulin, the patients were randomly assigned to receive either $2 \mathrm{~g}$ of metformin $(\mathrm{n}=13, \mathrm{MET}+$; Metforem, Orion, Espoo, Finland $)$ or a second injection of NPH insulin ( $n=13$, MET-).

Follow-up visits at 3 and 6 weeks, 3, 6, 9 and 12 months during insulin therapy. After the start of insulin therapy, the patients visited the doctor and the diabetes nurse at 3 and 6 weeks, 3, 6, 9 and 12 months. At these visits, which followed an overnight fast, body weight, blood pressure, hypoglycaemias and the insulin dosage were recorded, and a blood sample was taken for measurement of $\mathrm{HbA}_{1 \mathrm{c}}$ and plasma glucose concentrations. At 0 and 12 months, metabolic measurements addressing causes of weight gain were done as described below.

Metabolic measurements addressing causes of weight gain at 0 and 12 months. At these visits, which followed an overnight fast, a blood sample was taken for measurement of plasma glucose, serum-free insulin and serum leptin concentrations. Resting energy expenditure was measured with indirect calorimetry using the Deltatrac Metabolic Monitor (Datex, Helsinki, Finland). Samples of inspired and expired air, which were suctioned at $40 \mathrm{l} / \mathrm{min}$, were analysed for $\mathrm{O}_{2}$ and $\mathrm{CO}_{2}$ concentration differences using paramagnetic $\mathrm{O}_{2}$ and infrared $\mathrm{CO}_{2}$ analysers. The hood was placed on the subjects head $15 \mathrm{~min}$ before the measurements were started. The actual measurement lasted $60 \mathrm{~min}$. Urine was collected during the study and the protein oxidation rate was estimated from urea nitrogen excretion ( $1 \mathrm{~g}$ nitrogen $=6.25 \mathrm{~g}$ protein $)$. Glucose and lipid oxidation rates were calculated from the gas exchange data as previously described $[11,12]$. Body composition was determined using a single-frequency bioelectrical impedance device (Bio-Electrical Impedance Analyser System, Model No BIA-101 A, RJL Systems, Detroit, Mich., USA). Body mass was recorded to the nearest $0.1 \mathrm{~kg}$, and height to the nearest $0.5 \mathrm{~cm}$. The waist-to-hip ratio was measured as previously described [13]. Urine and blood samples were collected as described below. To assess energy intake, the patients were asked to keep a food record for 3 weekdays and 1 weekend day. This assessment was done by a dietetician who was not aware of the treat- 

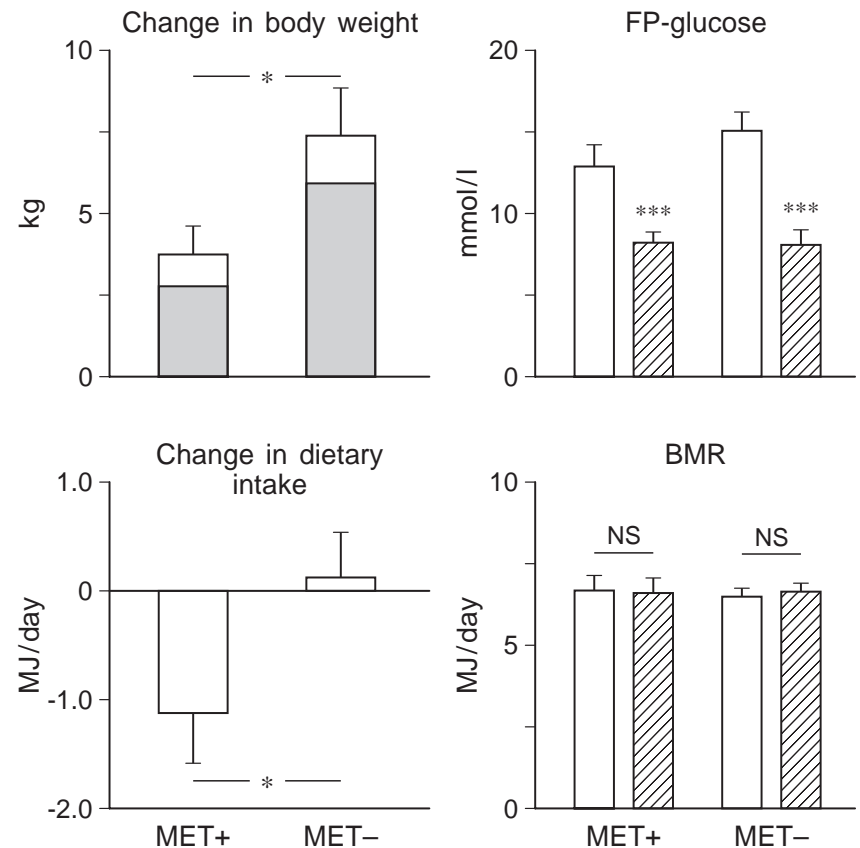

Fig. 1. Changes in body weight, dietary intake, fasting plasma glucose and BMR during 1 year of insulin therapy in MET + and MET-groups. The shaded bars in the upper left panel denote the fraction of weight gain, which could be attributed to an increase in fat mass. ${ }^{*} p<0.05,{ }^{* * * *} p<0.001$ for 0 vs 12 months or for difference between groups, as indicated in the figure

ment group of the patients. The nutrient energy intakes from the food records were analysed using a computerized diet analysis program (Micro-Nutrica 2.0, Kansaneläkelaitos, Turku, Finland), which contains the nutrient composition of foods used in Finland. The reproducibility of the method was examined by asking the patients to do two training recordings. The coefficient of variation for total energy intake was $8 \pm 1 \%$. The patients were asked to carry out a 24-h urine collection for determination of the energy lost in urine as glucose.

Informed written consent was obtained after the purpose, nature and potential risks were explained to the patients. The experimental protocol was designed and carried out according to the principles of Helsinki Declaration and was approved by the ethics committees of the Helsinki University Central Hospital and Jorvi Hospital.

Laboratory analyses. Plasma and urine glucose concentrations were measured in duplicate with the glucose oxidase method, using the Beckman Glucose Analyzer II (Beckman Instruments, Fullerton, Calif., USA). $\mathrm{HbA}_{1 \mathrm{c}}$ was measured by HPLC using the fully automated Glycosylated Hemoglobin Analyser System (BioRad, Richmond, Calif., USA). Serum fasting free insulin was determined by double antibody radioimmunoassay (Pharmacia Insulin RIA Kit, Pharmacia, Uppsala, Sweden) after precipitation with polyethylene glycol [14]. Serum fasting leptin concentration was determined by double antibody radioimmunoassay (Human Leptin RIA Kit, Linco Research Inc., St. Charles, Mo., USA).

Statistical analyses. Changes during insulin therapy between the MET + and MET- groups were compared using two-way analysis of variance for repeated measures. Simple correla-
Table 1. Characteristics of the Type II diabetic patients treated with insulin regimens either including $(\mathrm{MET}+)$ or not including (MET -) metformin

\begin{tabular}{|c|c|c|}
\hline & $\begin{array}{l}\mathrm{MET}+ \\
\text { group } \\
(n=13)\end{array}$ & $\begin{array}{l}\text { MET - } \\
\text { group } \\
(n=13)\end{array}$ \\
\hline Age (years) & $54 \pm 2$ & $58 \pm 3$ \\
\hline Body mass index $\left(\mathrm{kg} / \mathrm{m}^{2}\right)$ & $27.9 \pm 0.9$ & $27.8 \pm 1.1$ \\
\hline Body weight (kg) & $88 \pm 6$ & $87 \pm 4$ \\
\hline Fat (\% of body weight) & $27.5 \pm 1.2$ & $27.0 \pm 2.1$ \\
\hline Fasting plasma glucose $(\mathrm{mmol} / \mathrm{l})$ & $13.0 \pm 1.3$ & $15.2 \pm 1.0$ \\
\hline $\mathrm{HbA}_{1 \mathrm{c}}(\%)$ & $10.5 \pm 0.3$ & $10.2 \pm 0.3$ \\
\hline $\begin{array}{l}\text { Urinary albumin excretion rate } \\
(\mu \mathrm{g} / \mathrm{min})\end{array}$ & $20 \pm 5$ & $16 \pm 4$ \\
\hline $\begin{array}{l}\text { Bedtime NPH dose } \\
\text { (12 months, IU/day) }\end{array}$ & $41 \pm 12$ & $46 \pm 9$ \\
\hline $\begin{array}{l}\text { Morning NPH dose } \\
\text { (12 months, IU/day) }\end{array}$ & - & $32 \pm 5$ \\
\hline Serum triglycerides $(\mathrm{mmol} / \mathrm{l})$ & $3.2 \pm 0.4$ & $3.2 \pm 0.7$ \\
\hline
\end{tabular}

tions between selected study variables were calculated using Pearson's correlation coefficient for normally distributed variables. Multiple linear regression analysis was used to determine independent determinants of BMR. All calculations were made using the SYSTAT statistical package (sYSTAT Inc, Evanston, Il., USA). The slopes and intercepts of regression lines were compared as described in reference [15] using the GraphPad Prism (GraphPad Software Inc., San Diego, Calif., USA). All data are expressed as means \pm SEM.

\section{Results}

Glycaemic control, body weight, insulin and leptin concentrations. During the 12 months of insulin therapy, $\mathrm{HbA}_{1 \mathrm{c}}$ decreased from $10.5 \pm 0.3 \%$ by $2.9 \pm 0.2 \%$ to $7.6 \pm 0.2 \% \quad(p<0.001) \quad$ in the MET + group, and from $10.2 \pm 0.3 \%$ by $2.5 \pm 0.5 \%$ to $7.8 \pm 0.3 \%(p<0.001)$ in the MET- group (changes NS between the groups). Fasting plasma glucose also decreased similarly in MET + and MET-groups (Fig. 1). The MET + group required $47 \%$ less insulin than the MET- group to achieve similar glycaemic control (Table 1).

The MET + group gained $3.8 \pm 0.8 \mathrm{~kg}(p<0.001$ for 12 vs 0 months) during insulin therapy, which was $49 \%$ less $(p<0.05)$ than in the MET- group $(7.5 \pm 1.6 \mathrm{~kg}, p<0.001$ for 12 vs 0 months) (Fig. 1$)$. $\mathrm{BMI}$ increased $53 \%$ less in the MET $+(1.3 \pm 0.2 \mathrm{~kg} /$ $\left.\mathrm{m}^{2}\right)$ than in the MET $-\left(2.8 \pm 0.6 \mathrm{~kg} / \mathrm{m}^{2}\right)$ group. Body fat content increased ( $p<0.001$ for both) during insulin therapy in both groups but the increase was smaller in the MET $+(2.8 \pm 0.7 \mathrm{~kg})$ than the MET$(5.2 \pm 0.8 \mathrm{~kg})$ group $(p<0.05)$. The waist-to-hip ratio changed (12 vs 0 months) by $-0.004 \pm 0.012$ in the MET + group and by $0.021 \pm 0.015$ in the MET - (NS between the groups). 


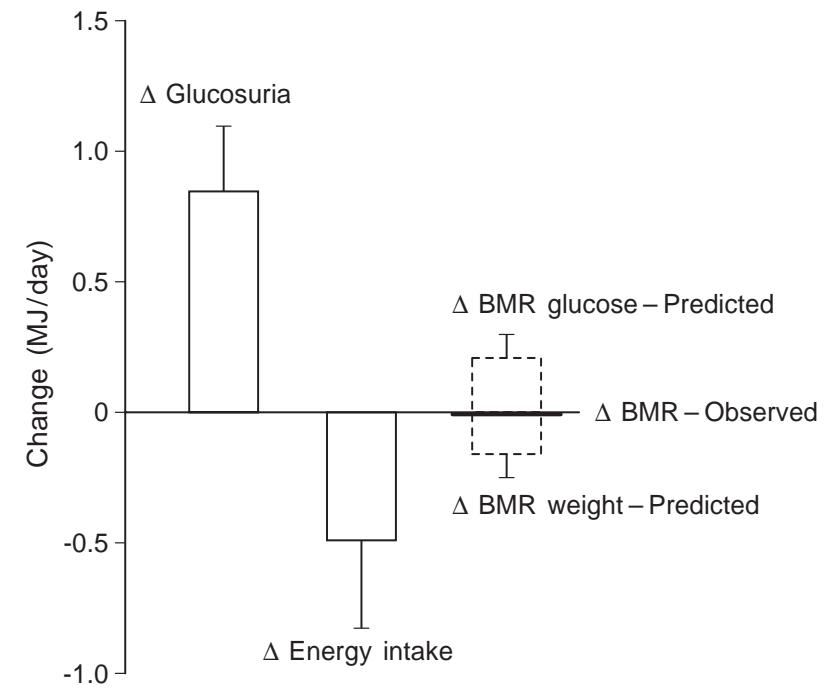

Fig. 2. Changes in glucosuria, energy intake and BMR during 1 year of insulin therapy. $\triangle \mathrm{BMR}$ - Observed denotes the measured change in BMR. $\triangle \mathrm{BMR}$ weight - Predicted and $\triangle \mathrm{BMR}$ glucose - Predicted denote the predicted change in BMR based on observed changes in body weight and the fasting plasma glucose concentration (see "Results" for the multiple linear regression equation and other calculations)

The fasting serum-free insulin concentration increased from $13 \pm 1$ at 0 months to $17 \pm 3 \mathrm{mU} / \mathrm{l}$ at 12 months in the MET + group (NS) and from $11 \pm 2$ to $16 \pm 2 \mathrm{mU} / \mathrm{l}(p<0.01)$ in the MET-group. Serum leptin concentrations increased by $43 \%$ from $8.8 \pm 1.1$ to $12.6 \pm 1.7$ in the MET + group $(p<0.005)$ and by $61 \%$ from $9.2 \pm 1.9$ to $14.8 \pm 2.9 \mathrm{mU} / \mathrm{l}(p<0.005)$ in the MET- group (NS between groups). Both the change in body weight $(r=0.72, p<0.001)$ and the change in serum-free insulin $(r=0.56, p<0.005)$ were significantly correlated with the change in serum leptin concentrations. The slopes or intercepts characterizing these relations within the MET + and METgroups were not different (data not shown) implying that use of metformin in itself had no effect on the interrelation between these variables.

Components of energy balance. The BMR, expressed per $\mathrm{kg}$ body weight, decreased by $5 \%$ in all patients $\left(59 \pm 4\right.$ vs $\left.56 \pm 4 \mathrm{~J} \cdot \mathrm{kg}^{-1} \cdot \mathrm{min}^{-1}, p<0.001\right)$ and in both $\mathrm{MET}+\left(61 \pm 2\right.$ vs $57 \pm 1 \mathrm{~J} \cdot \mathrm{kg}^{-1} \cdot \mathrm{min}^{-1}, 0$ vs 12 months, $p<0.01)$ and MET- $(62 \pm 2$ vs $59 \pm 2$ $\mathrm{J} \cdot \mathrm{kg}^{-1} \cdot \mathrm{min}^{-1}, 0$ vs 12 months, $\left.p<0.05\right)$ groups. Absolute energy expenditure remained unchanged in all patients and the MET $+(6.77 \pm 0.36$ vs $6.67 \pm 0.34$ $\mathrm{MJ} /$ day $)$ and the MET- $(6.57 \pm 0.22$ vs $6.64 \pm 0.24$ $\mathrm{MJ} /$ day) groups (Fig.1). At 0 months, the fasting plasma glucose concentration $(p<0.02)$ and body weight $(p<0.001)$ explained $75 \%$ of the variation in BMR. From the equation relating the change in fasting glucose and the change in body weight to the change in BMR [change in BMR $(\mathrm{kJ} /$ day $)=50+36$
Table 2. Dietary composition at 0 and 12 months

\begin{tabular}{lcccc}
\hline & $\begin{array}{l}\text { MET }+ \\
0 \text { months }\end{array}$ & $\begin{array}{l}\text { MET }- \\
0 \text { months }\end{array}$ & $\begin{array}{l}\text { MET }+ \\
12 \text { months }\end{array}$ & $\begin{array}{l}\text { MET }- \\
12 \text { months }\end{array}$ \\
\hline \% of energy from & & & & \\
Fat & $37 \pm 1$ & $37 \pm 2$ & $35 \pm 2$ & $40 \pm 2^{\mathrm{a}}$ \\
Carbohydrate & $37 \pm 3$ & $40 \pm 2$ & $41 \pm 2$ & $39 \pm 4$ \\
Protein & $18 \pm 2$ & $20 \pm 1$ & $20 \pm 1$ & $19 \pm 1$ \\
Alcohol & $4 \pm 2$ & $3 \pm 1$ & $4 \pm 2$ & $2 \pm 2$ \\
Cholesterol & & & & \\
(mg/day) & $355 \pm 25$ & $316 \pm 35$ & $254 \pm 28$ & $288 \pm 26$ \\
Fibre (g/day) & $26 \pm 1$ & $22 \pm 2$ & $23 \pm 2$ & $22 \pm 3$ \\
\hline${ }^{a} p<0.05$ for Met + vs MET - group & &
\end{tabular}

$*$ change in fasting glucose $(\mathrm{mmol} / \mathrm{l})+28 *$ change body weight $(\mathrm{kg})$ ], it could be calculated, that the observed improvement in glycaemia $(5.8 \mathrm{mmol} / \mathrm{l})$ corresponded to a $213 \mathrm{~kJ} /$ day decrease in BMR and the increase in body weight $(5.7 \mathrm{~kg})$ to an increase of BMR of $163 \mathrm{~kJ} /$ day (Fig. 2). The predicted difference between these opposite changes (decrease in BMR of $50 \mathrm{~kJ} /$ day) was not different from the observed change in BMR of $8 \mathrm{~kJ} /$ day. The non-protein respiratory quotients averaged $0.763 \pm 0.027$ and $0.768 \pm 0.019$ in the MET + and MET- groups at 0 months. It increased slightly but not statistically significantly during insulin therapy and averaged $0.783 \pm 0.024$ and $0.784 \pm 0.021$ in the MET + and MET- groups at 12 months (NS between groups). Consequently, rates of carbohydrate and lipid oxidation also remained unchanged. Protein oxidation was similar at baseline in both groups and remained unchanged during insulin therapy (data not shown).

Energy intake decreased by $1.12 \pm 0.46 \mathrm{MJ} /$ day in the MET + group and increased by $0.15 \pm 0.42 \mathrm{MJ} /$ day in the MET- group ( $p<0.05$ between groups) and by $0.48 \pm 0.34 \mathrm{MJ} /$ day (NS vs 0 ) in the entire group (Fig.1). Total energy intake averaged $7.96 \pm 0.41 \mathrm{MJ} /$ day at 0 months and $7.47 \pm 0.34 \mathrm{MJ} /$ day at 12 months. The composition of the diet remained unchanged except for the percentage of energy derived from fat, which was considerably lower at 12 months in the MET + than in the MET- group (Table 2). The reproducibility of the energy intake recordings was similar in the MET $+(7 \pm 2 \%)$ and MET $-(8 \pm 2 \%)$ groups.

Glucosuria was observed at glucose concentrations exceeding $10 \mathrm{mmol} / \mathrm{l}$, and increased thereafter in proportion to the fasting plasma glucose concentration (Fig. 3). For every $5 \mathrm{mmol} / \mathrm{l}$ increment in plasma glucose above $10 \mathrm{mmol} / \mathrm{l}$, glucosuria increased by $1.41 \mathrm{MJ} /$ day (Fig. 3). During 12 months of insulin therapy, glucosuria decreased considerably and by $0.83 \pm 0.27 \mathrm{MJ} /$ day (Fig. 2), with no difference between the MET + and MET-groups. In the entire group, the change in the fasting plasma glucose concentration was inversely correlated with weight gain 

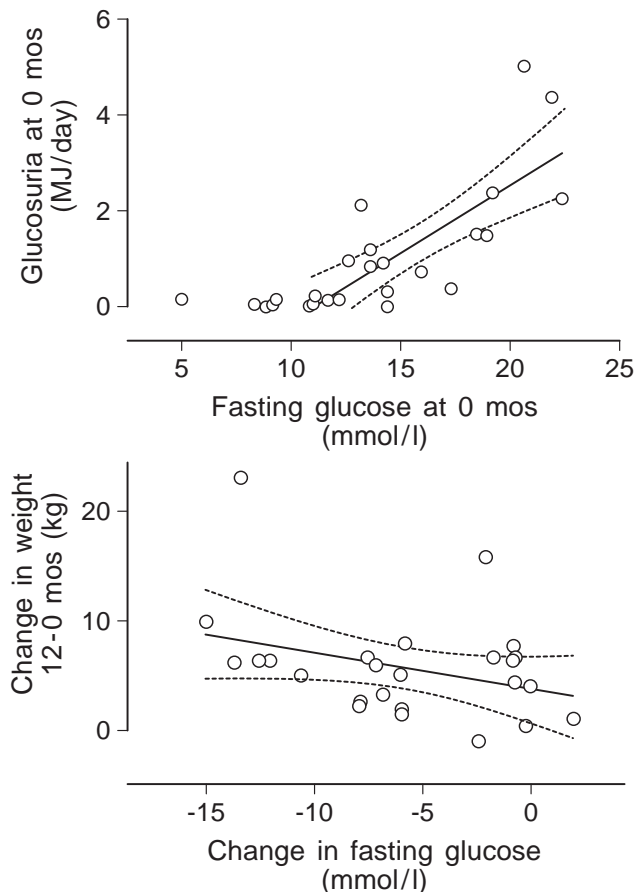

Fig. 3. Top panel: The relation between the fasting plasma glucose concentration and glucosuria before insulin therapy. The regression line and its confidence intervals denote the relation between fasting glycaemia and glucosuria at glucose concentrations exceeding $10 \mathrm{mmol} / \mathrm{l}$. Bottom panel: The relation between the change in fasting plasma glucose and the change in body weight during 1 year of insulin therapy

(Fig.3). Such an inverse relation was also observed within the MET + group $(r=-0.50, p<0.05)$ but not within the MET- group. Thus, regarding the overall energy balance, given the lack of change in the absolute BMR and the similar changes in glycaemia in MET + and MET- groups, the difference in weight gain between the groups could be attributed to the difference in energy intake between the groups (Fig.1). Figure 2 depicts energy balance for all patients during insulin therapy. The net energy balance, assuming constant activity and thermogenesis, was positive [change in glucosuria $(0.83 \mathrm{MJ} /$ day $)+$ change in energy intake $(-0.48 \mathrm{MJ} /$ day $)+$ change in BMR $(-0.008 \mathrm{MJ} /$ day) $]$ and averaged $0.34 \mathrm{MJ} /$ day $(\mathrm{Ta}-$ ble 3). Assuming all of this energy was stored as fat and that $1 \mathrm{~kg}$ of fat corresponds to $37.7 \mathrm{MJ}$, the measurements predicted a gain in fat of $3.3 \mathrm{~kg}$ (Table 3).

\section{Discussion}

This study analysed causes of weight gain during insulin therapy in patients with Type II diabetes who were (MET + group) or were not (MET- group) using metformin. Glycaemic control improved similarly in both groups. In keeping with previous data, metform-
Table 3. Changes in components of energy balance before and after 1 year of insulin therapy

\begin{tabular}{lllc}
\hline & Before & After & Change/patient \\
\hline $\mathrm{E}_{\mathrm{IN}}(\mathrm{MJ} /$ day $)$ & $7.96 \pm 0.41$ & $7.47 \pm 0.34$ & $-0.48 \pm 0.34$ \\
$\mathrm{E}_{\text {OUT }}(\mathrm{MJ} /$ day $)$ & & & \\
- glucosuria & $1.05 \pm 0.25$ & $0.22 \pm 0.07^{\mathrm{a}}$ & $0.83 \pm 0.27$ \\
- BMR & $6.66 \pm 0.21$ & $6.65 \pm 0.20$ & $0.008 \pm 0.001$ \\
& & Net gain & $0.34 \mathrm{MJ} /$ day \\
\hline
\end{tabular}

The net gain of $0.34 \mathrm{MJ} /$ day corresponds to a gain of $124.1 \mathrm{MJ} /$ year per patient. This corresponds to a gain of $3.3 \mathrm{~kg}$ fat, which is close to the observed gain in fat mass $(4.0 \mathrm{~kg}) .{ }^{\mathrm{a}} p<0.001$ after vs before insulin therapy

in had an insulin sparing effect, i. e. less insulin was required in the MET + than the MET-group for a similar decrease in blood glucose concentrations [16]. In the entire group, improvement in glycaemia favoured weight gain by decreasing the energy lost in the urine as glucose and by decreasing BMR. Weight gain itself increased energy expenditure by increasing the BMR. In addition to these factors, which changed similarly in the MET + and MET- groups, dietary intake decreased appreciably in the MET + compared with the MET- group and explained why the MET + group gained less weight than the METgroup.

The BMR is known to be tightly correlated with body weight, especially lean body mass [17]. This was also true in this study. In addition, we found the degree of glycaemic control to be an important determinant of BMR (expressed per body weight), which decreased by $5 \%$ when fasting glucose decreased by $5.9 \mathrm{mmol} / \mathrm{l}$. This finding is almost identical to the $5 \%$ decrease in BMR observed during 6 weeks of tolazamide therapy in nine patients with Type II diabetes, whose fasting glucose concentration decreased by $6 \mathrm{mmol} / \mathrm{l} \mathrm{[18]}$ and supports the idea that the decrease in BMR, per $\mathrm{kg}$ body weight is due to improved glycaemia rather than the mode of therapy. A decrease in BMR per body weight has also been observed during insulin therapy [4]. The exact mechanisms underlying the correlation between glycaemia and BMR have not been established but have been attributed to the energy cost of increased gluconeogenesis [19, 20] and glucose cycling [21] under hyperglycaemic conditions. It is also possible that glucose merely serves as a marker of multiple consequences of insulin deficiency on not only glucose but also on protein and lipid metabolism, which all include energy consuming components. Data are sparse regarding rates of protein catabolism in Type II diabetes but one study suggested that protein catabolism is normal in poorly controlled patients with Type II diabetes [22]. Insulin therapy is also known to noticeably lower plasma non-esterified fatty acid concentrations, a change which is associated with a lowering of of gluconeogenesis [23]. A decrease in non-esterified fatty 
acid concentrations may also lower heat production by decreasing mitochondrial uncoupling, i.e. the ratio between heat and ATP production [24].

Although BMR, expressed per body weight, decreased appreciably, absolute BMR remained unchanged. This finding is similar to that observed previously during insulin therapy [4] and metformin monotherapy [9] but extends earlier findings by showing that the lack of change in BMR can, at least statistically, be attributed to two components influencing BMR in opposite directions. In this study, the decrease in BMR associated with improved glycaemia was statistically similar to the increase in BMR induced by weight gain. The clinical implication of these data is that even if energy intake is reduced by an amount corresponding to glucosuria, weight gain will still occur because the improvement in glycaemic control in itself (or some associated metabolic change, vide supra) will decrease energy expenditure.

The mechanism underlying the weight gain sparing effect of metformin has been long debated but no studies systematically analysing the causes of weight gain are available. Although studies in animals suggested biguanides decrease glucose absorption [25], inhibition of glucose absorption by metformin has only been observed in one study in nondiabetic subjects and this result has not been confirmed [26]. In contrast to these data, another study found the rate of appearance of radiolabelled glucose given orally to be unaffected by metformin, suggesting that the drug has no effect on glucose absorption. In our study, the weight sparing effect of metformin could be attributed to dietary intake, which decreased considerably in the patients using metformin during insulin therapy. Analysis of dietary intake by the food record method might be regarded unreliable in small studies; however, here, using a a blinded study design, the assessment was done by a dietician with considerable experience in the use of this method in both metabolic and large-scale intervention studies. Also, methodological noise would probably result in a type 2 error, which did not happen. In keeping with the present data, 3 days of treatment with metformin has been reported to decrease the feeling of hunger and food consumption [8]. In our study, the patients did not report gastrointestinal side effects but we cannot exclude the possibility that subclinical abdominal discomfort or the taste of metformin contributed to the decrease in dietary intake. Except for dietary intake, metformin had no effect on other factors which might influence energy balance. Serum leptin concentrations increased in both MET + and MET - groups during insulin therapy but the magnitude of the increase was readily explained by changes in insulin concentrations and changes in body weight.

In this study, weight gain averaged $7.5 \mathrm{~kg}$ in the MET-group. This increase is large but has to be re- lated to the improvement in glycaemic control, which averaged $2.5 \%$ as determined by $\mathrm{HbA}_{1 \mathrm{c}}$. In a previous multicentre study comparing different insulin treatment regimens, weight gain over 1 year averaged $4.8 \mathrm{~kg}$ in 50 patients treated with insulin alone. $\mathrm{HbA}_{1 \mathrm{c}}$ decreased by $1.2 \%$ in these patients [3]. In another study where insulin alone was used, weight gain averaged $3.9 \mathrm{~kg}$ during 1 year and $\mathrm{HbA}_{1 \mathrm{c}}$ decreased by $1.7 \%$ [4]. In the UKPDS, weight gain averaged 2.5 $\mathrm{kg}$ and $\mathrm{HbA}_{1 \mathrm{c}}$ decreased by $0.7 \%$ during the first year of treatment in patients using either sulphonylureas or insulin [2]. These data suggest, as was observed within the entire study group and within the MET + group, that the change in glycaemia is a significant predictor of the magnitude of weight gain. We did not assess the change in weight before insulin therapy was started in the study participants. In Pima Indians followed longitudinally, weight loss occurs prior to diagnosis of Type II diabetes, and weight gain is observed after start of treatment [27]. Thus, part of weight gain during any successful treatment of hyperglycaemia can be regarded as physiological. In the Finnish Multicentre Insulin Therapy study (FINMIS) [3, 10], positive correlations were observed within the various treatment groups between improvement in glycaemia and weight gain during the first 3 months of therapy. These relations were gradually lost during the first year (unpublished data), suggesting that initial weight gain may reflect restoration of consequences of insulin deficiency. A practical interpretation of these data is that in clearly hyperglycaemic patients, a greater degree of weight gain can be considered acceptable than in those who are moderately hyperglycaemic (Fig.3). One may also ask whether any weight gain is indeed harmful. In the FINMIS study, weight gain in the 100 patients followed for 1 year was positively correlated with statistically significant increases in blood pressure and LDL cholesterol $[3,10]$. These data show that excessive weight gain may adversely affect cardiovascular risk factors, although striking beneficial effects, e.g. in serum lipid and lipoprotein concentrations [28] and insulin sensitivity [29], can be observed during short-term insulin therapy [28]. The true importance of changes in body weight for the development cardiovascular disease awaits final analysis of the UKPDS data in the various treatment groups.

In conclusion, several factors influence weight gain during insulin therapy in patients with Type II diabetes. These include, assuming constant activity and thermogenesis, the magnitude of improvement in glycaemic control, the degree of weight gain in itself, dietary intake and use of metformin. Improved glycaemia promotes weight gain by reducing both BMR and glucosuria. The latter is counterbalanced by an increase in BMR caused by weight gain. Use of metformin decreases weight gain by decreasing energy intake and can therefore be recommended to be 
used in combination with insulin in patients with Type II diabetes.

Acknowledgements. We thank Ms. L.Pekkonen for excellent patient guidance, Ms. S. Haapanen and Ms. K. Tuomola for superb technical assistance, Ms. H. Schmidt for drawing the figures and the volunteers for their help. S. Mäkimattila is supported by grants from the Finnish Medical Society Duodecim and the Lehikoinen and Orion research foundations. H. YkiJärvinen is supported by grants from the Academy of Finland, the Sigrid Juselius and Ahokas research foundations.

\section{References}

1. Turner R, Cull C, Holman R (1996) United Kingdom Prospective Diabetes Study 17: a 9-year update of a randomized, controlled trial on the effect of improved metabolic control on complications in non-insulin-dependent diabetes mellitus. Ann Intern Med 124: 136-145

2. U.K. Prospective Diabetes Study Group (1995) U.K. Prospective Diabetes Study 16. Overview of 6 years' therapy of type II diabetes: a progressive disease. Diabetes 44: 1249-1258

3. Yki-Järvinen H, Ryysy L, Kauppila M et al. (1997) Effect of obesity on the response to insulin therapy in noninsulin-dependent diabetes mellitus. J Clin Endocrinol Metab 82: 4037-4043

4. Franssila-Kallunki A, Groop L (1992) Factors associated with basal metabolic rate in patients with type 2 (non-insulin-dependent) diabetes mellitus. Diabetologia 35: 962-966

5. Welle S, Nair KS, Lockwood D (1988) Effect of a sulfonylurea and insulin on energy expenditure in type II diabetes mellitus. J Clin Endocrinol Metab 66: 593-597

6. Shank ML, Del Prato S, DeFronzo RA (1995) Bedtime insulin/daytime glipizide: Effective therapy for sulfonylurea failures in NIDDM. Diabetes 44: 165-172

7. DeFronzo RA, Goodman AM (1995) Efficacy of metformin in patients with non-insulin-dependent diabetes mellitus. The Multicenter Metformin Study Group. N Engl J Med 333: 541-549

8. Lee A, Morley JE (1998) Metformin decreases food consumption and induces weight loss in subjects with obesity with type II non-insulin-dependent diabetes. Obes Res 6: $47-53$

9. Stumvoll M, Nurjhan N, Perriello G, Dailey G, Gerich JE (1995) Metabolic effects of metformin in non-insulin-dependent diabetes mellitus. N Engl J Med 333: 550-554

10. Yki-Järvinen H, Kauppila M, Kujansuu E et al. (1992) Comparison of insulin regimens in patients with non-insulin-dependent diabetes mellitus. N Engl J Med 327: 1426-1433

11. Yki-Järvinen H, Puhakainen I, Saloranta C, Groop L, Taskinen M-R (1991) Demonstration of a novel feedback mechanism between FFA oxidation from intracellular and intravascular sources. Am J Physiol 260: E680-E689

12. Ferrannini E (1988) The theoretical bases of indirect calorimetry: a review. Metab Clin Exp 37: 287-301
13. Ohlson L-0, Larsson B, Svärdsudd K, Welin K et al. (1985) The influence of body fat distribution on the incidence of diabetes mellitus. 13.5 years of follow-up of the participants in the study of men in 1913. Diabetes 34: 1055-1058

14. Desbuquois B, Aurbach GD (1971) Use of polyethylene glycol to separate free and antibody-bound peptide hormones in radioimmunoassay. J Clin Endocrinol Metab 33: 732-738

15. Armitage P (1971) Statistical methods in medical research. 1st edn. Blackwell Scientific Publications, Oxford, pp 279-284

16. Giugliano D, Quatraro A, Consoli G et al. (1993) Metformin for obese, insulin-treated diabetic patients: improvement in glycaemic control and reduction of metabolic risk factors. Eur J Clin Pharmacol 44: 107-112

17. Ravussin E (1993) Energy metabolism in obesity. Studies in the Pima Indians. Diabetes Care 16: 232-238

18. Bogardus C, Taskinen M-R, Zawadzki J, Lillioja S, Mott D, Howard BV (1986) Increased resting metabolic rates in obese subjects with non-insulin-dependent diabetes mellitus and the effect of sulfonylurea therapy. Diabetes 35: 1-5

19. Magnusson I, Rothman DL, Katz LD, Shulman RG, Shulman GI (1992) Increased rate of gluconeogenesis in type II diabetes mellitus. A ${ }^{13} \mathrm{C}$ nuclear magnetic resonance study. J Clin Invest 90: 1323-1327

20. Consoli A, Nurjhan N, Capani F, Gerich J (1989) Predominant role of gluconeogenesis in increased hepatic glucose production in NIDDM. Diabetes 38: 550-557

21. Efendic S, Wajngot A, Vranic M (1985) Increased activity of the glucose cycle in the liver: an early characteristic of type 2 diabetes. Proc Natl Acad Sci 82: 2965-2969

22. Umpleby AM, Scobie IN, Boroujerdi MA, Carson ER, Sönksen PH (1990) Diurnal variation in glucose and leucine metabolism in non-insulin-dependent diabetes. Diabetes Res Clin Pract 9: 89-96

23. Yki-Järvinen H, Helve E, Sane T, Nurjhan N, Taskinen M$\mathrm{R}$ (1989) Insulin inhibition of overnight glucose production and gluconeogenesis from lactate in NIDDM. Am J Physiol 256: E732-E739

24. Himms-Hagan J (1976) Cellular thermogenesis. Ann Rev Physiol 37: 315-351

25. Caspary WF (1977) Biguanides and intestinal absorptive function. Acta Hep Gastroenterol 24: 473-480

26. Hermann LS, Melander A (1992) Biguanides: basic aspects and clinical uses. In: Alberti KGMM, DeFronzo RA, Keen $\mathrm{H}$, Zimmet $\mathrm{P}$ (eds) International Textbook of Diabetes Mellitus. John Wiley \& Sons, Chichester, pp 773-795

27. Knowler WC, Pettitt DJ, Savage RJ, Bennett PH (1981) Diabetes incidence in Pima Indians: contributions of obesity and parental diabetes. Am J Epidemiol 113: 144-156

28. Taskinen M-R, Kuusi T, Helve E, Nikkilä E, Yki-Järvinen $\mathrm{H}$ (1988) Insulin therapy induces antiathrogenic changes in serum lipoproteins in non-insulin-dependent diabetes mellitus. Arteriosclerosis 8: 168-177

29. Yki-Järvinen H, Nikkilä E, Helve E, Taskinen M-R (1988) Clinical benefits and mechanisms of a sustained response to intermittent insulin therapy in type 2 diabetic patients with secondary drug failure. Am J Med 84: 185-192 